\title{
INCOR: ALÉM DA ASSISTÊNCIA
}

A recente discussão sobre aspectos financeiros do Instituto do Coração do Hospital das Clínicas da Faculdade de Medicina da Universidade de São Paulo (Incor) expôs alguns problemas dos hospitais universitários como um todo.

O Incor alcançou projeção internacional graças a alguns fatores:

I. Atendimento médico volumoso, moderno, diversificado, cobrindo todas as áreas da Cardiologia, em adultos e crianças; realização de todos os procedimentos atuais com técnicas modernas em Bioquímica, Imagenologia (ecocardiograma, radioisótopos, ressonância magnética, tomografias), Hemodinâmica, arritmias, Cirurgia Cardíaca, marcapassos; atendimento médico integrado com assistentes sociais, enfermagem, psicólogos, técnicos nas mais diversas áreas. No Incor, realizam-se procedimentos de alta complexidade, com comprovada eficiência. Oitenta por cento de tudo isso, em todos os níveis, dedicam-se a pacientes Sistema Único de Saúde (SUS).

2. Ensino de graduação e pós-graduação; alunos dos terceiro, quarto e sexto anos da USP treinam no Incor; a pós-graduação stricto sensu tem 146 alunos; 21 teses foram apresentadas no ano passado. A residência do Incor tem 87 internos, sendo uma das mais procuradas do País, na proporção de cinco candidatos por vaga.

3. Estrutura de pesquisa profissional, com laboratórios de investigação básica como biologia molecular e investigação clínica em todas as áreas da Cardiologia. Mas principalmente tem pesquisadores capacitados, trabalhando em tempo integral; a maioria destes tem doutorado, e muitos, pos doc no exterior. Em conseqüência, grande número de publicações científicas e apresentações em congressos são geradas a cada ano. Em 2005, 213 trabalhos nacionais e 203 internacionais foram publicados. Em suma, contribuições significativas para o progresso da Cardiologia têm sido dadas regularmente pelo Incor.

Há algumas explicações para isso: as equipes têm tradição; o trabalho conjunto das equipes médicas e cirúrgicas tem mais de 50 anos, desde Zerbini e Décourt. Os médicos, em grande parte, trabalham em tempo integral; a remuneração deles não depende só do Estado - a Fundação Zerbini suplementa ou paga integralmente seus salários; há renovação constante de seus quadros e programa permanente de treinamento no exterior.

Freqüentemente, porém, quando se analisa o desempenho do Incor de forma objetiva, só se considera a questão assistencial, quanto custa tratar de doentes. Produção científica e ensino parece que nada custam e, portanto, nada valem. Aliás, há um custo estimado do cuidado médico, tanto particular quanto de convênios e SUS. Por exemplo, um cateterismo cardíaco, incluindo honorários médicos, custa 2500 reais pela tabela da Associação Médica Brasileira; uma consulta médica por convênios custa em média 30 reais. Ou seja, estas entidades usam essas tabelas de custo para ressarcir os diagnósticos e tratamentos médicos.
Em contraposição, não temos um custo, mesmo que estimado, da produção científica. Quanto custa um trabalho cientííco quando sai publicado? Quanto custa o desenvolvimento de uma prótese de válvula cardíaca? Ou a produção de um ventrículo artificial produzido no Incor?

É evidente que o Incor, ou qualquer hospital universitário, não pode ser avaliado apenas pelo trabalho assistencial, como se fosse um hospital de bairro, que apenas trata de doentes. $O$ hospital universitário, além de cuidados médicos de alto nível, gera novos conhecimentos e instrução, que se revertem em benefício da população. Por outro lado, exerce papel fundamental na triagem de equipamentos e novas tecnologias desenvolvidos no primeiro mundo, e que são utilizados por todo o sistema de saúde no País.

Assim, esse critério de avaliação baseado apenas em assistência médica precisa ser revisto pelo órgãos governamentais quando se discute orçamentos e destinação de verbas. Uma solução seria considerar os custos da assistência e da pesquisa, com igual prioridade, como intrínsecos à natureza do hospital universitário. Deveríamos criar uma estrutura administrativa que permitisse obter financiamentos específicos para pesquisa/ desenvolvimento e que possa fornecer recursos por meio da Secretaria de Ciência e Tecnologia, como se o hospital universitário fosse um de seus institutos de pesquisa. Isto permitiria incorporar despesas com pessoal, equipamentos, instalações, manutenção e custeio. A Fundação de Amparo à Pesquisa do Estado de São Paulo, que tem enorme contribuição para a ciência e tecnologia em nosso Estado, financia projetos de pesquisa, mas tem ação bem específica. Por exemplo, não financia pessoal e infra-estrutura.

Quem deveria pagar por uma estrutura assim? Primeiro, o próprio Estado, porque ele é responsável pela saúde dos cidadãos e também pelo desenvolvimento tecnológico do País. Igualmente, deve ser responsabilidade da sociedade civil em geral, porque ela é beneficiária direta do desenvolvimento gerado pelo hospital universitário. E aqui entram as fundações de apoio às entidades universitárias. Já que o Estado não tem recursos para atender às necessidades do País em saúde, pesquisa e desenvolvimento, a sociedade civil deve ajudar. As fundações de apoio são o veículo para fazer isso.

A sociedade civil tem dado mostras de que é sensível a essas necessidades e reconhecido interesses comuns com as universidades e entidades acadêmicas. As ações conjuntas universidade/empresa bem como públicas/privadas são uma tendência positiva de políticas modernas. No que concerne aos hospitais universitários, precisamos de uma mudança de conceitos; precisamos de uma inovação que considere sua participação no campo da pesquisa e do ensino. É necessária uma ação coordenada, persistente das entidades universitárias, governamentais e civis para elaborar programas que visem o desenvolvimento científico/tecnológico em benefício da comunidade.

Protásio L. dA Luz São Paulo - SP 